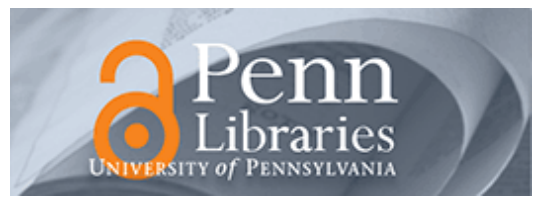

University of Pennsylvania

ScholarlyCommons

Operations, Information and Decisions Papers

Wharton Faculty Research

1980

\title{
Efron's Conjecture on Vulnerability to Bias in a Method for Balancing Sequential Trials
}

\author{
J. Michael Steele \\ University of Pennsylvania
}

Follow this and additional works at: https://repository.upenn.edu/oid_papers

Part of the Biometry Commons, and the Other Mathematics Commons

\section{Recommended Citation}

Steele, J. (1980). Efron's Conjecture on Vulnerability to Bias in a Method for Balancing Sequential Trials. Biometrika, 67 (2), 503-504. http://dx.doi.org/10.1093/biomet/67.2.503

This paper is posted at ScholarlyCommons. https://repository.upenn.edu/oid_papers/106

For more information, please contact repository@pobox.upenn.edu. 


\title{
Efron's Conjecture on Vulnerability to Bias in a Method for Balancing Sequential Trials
}

\author{
Abstract \\ Efron (1971) proposed a method for sequential assignment to treatments or control which is in many \\ ways superior to traditional procedures. To analyse the method's susceptibility to accidental bias a \\ criterion concerning the maximum eigenvalue of a fundamental covariance matrix was introduced. On the \\ basis of numerical evidence, Efron conjectured an explicit formula for this eigenvalue. This note gives a \\ proof of that conjecture.
}

\section{Keywords}

balanced experiment, biased coin design, covariance matrix, maximum eigenvalue, sequential trial

\section{Disciplines}

Biometry | Other Mathematics 


\title{
EFRON'S CONJECTURE ON VULNERABILITY TO BIAS IN
} A METHOD FOR BALANCING SEQUENTIAL TRIALS

\author{
BY \\ J. MICHAEL STEELE
}

TECHNICAL REPORT NO. 148

OCTOBER 1979

\author{
PREPARED UNDER THE AUSPICES \\ $\mathrm{OF}$ \\ NATIONAL SCIENCE FOUNDATION GRANT \\ MCS 78-07736 \\ Ingram 01kin, Project Director
}

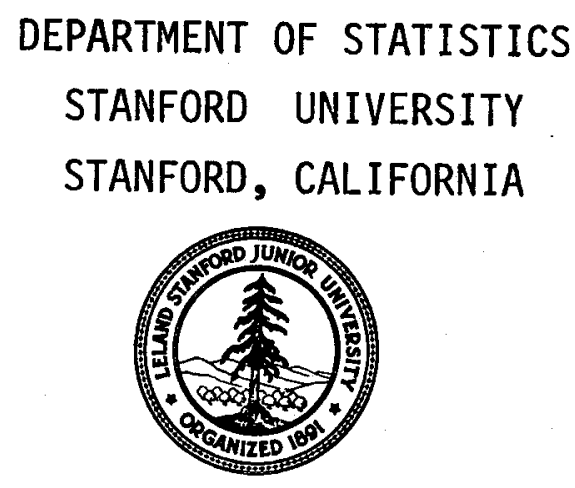


EFRON'S CONJECTURE ON VULNERABILITY TO BIAS IN

A METHOD FOR BALANCING SEQUENTIAL TRIALS

by

'J. Michael Steele

TECHNICAL REPORT NO. 148

OCTOBER 1979

PREPARED UNDER THE AUSPICES

OF

NATIONAL SCIENCE FOUNDATION GRANT

MCS 78-07736

Ingram 01kin, Project Director

DEPARTMENT OF STATISTICS

STANFORD UNIVERSITY

STANFORD, CALIFORNIA 
EFRON'S CONJECTURE ON VULNERABILITY TO BIAS IN

A METHOD FOR BALANCING SEQUENTIAL TRIALS

by

J. Michael Steele

Department of Statistics

Stanford University

Abstract. Efron (1971) proposed a method for sequential assignment to treatments or control which is in many ways superior to traditional procedures. To analyze the method's susceptability to accidental bias a criterion concerning the maximum eigenvalue of a fundamental covariance matrix was introduced. On the basis of numerical evidence, Efron conjectured an explicit formula for this eigenvalue. This note gives a proof of Efron's conjecture.

Key Words. Balanced experiment, biased coin design, covariance matrix, maximum eigenvalue, sequential trials. 


\section{Efron's Biased Coin Design}

Suppose subjects are to be assigned sequentially to either treatment or control. If at the time of arrival of a new subject there have been $D$ more subjects assigned to treatment than control, then Efron (1971) suggests the following action:

If $\mathrm{D}>0$, assign treatment with probability $\mathrm{q}$ and control with probability p.

If $D=0$, assign treatment with probability $1 / 2$ and control with probability $1 / 2$.

If $\mathrm{D}<0$, assign treatment with probability $\mathrm{p}$ and control with probability $q$.

This is Efron's biased coin design and will be denoted by $\operatorname{BCD}(\mathrm{p})$. This procedure has several benefits over some traditional procedures such as the student sandwich plan, and it has attracted considerable practical and theoretical attention (e.g., Matts and McHugh (1978), Pocock (1979), Pocock and Simon (1975), and Wei (1977, 1978)).

Now suppose that $\mathrm{N}$ subjects have been assigned to treatment via a $B C D(p)$ and let $T_{k}$ be +1 or -1 accordingly as the $k$ th subject is assigned to treatment or control. The vector $\bar{T}=\left(T_{1}, T_{2}, \ldots, T_{n}\right)$ has mean $\mathrm{E}(\overline{\mathrm{T}})=0$, and its covariance matrix will be denoted $\$$.

After introducing the biased coin designs Efron (1971) argued persuasively (pp. 408-409) that the vulnerability of a balancing design to an accidental bias is sensibly measured by the maximum eigenvalue of the covariance matrix $\$$. This in turn was studied by considering the maximum eigenvalue $\lambda_{N}$ of the asymptotic covariance 
of the vector $\left(T_{h+1}, T_{h+2}, \ldots, T_{h+N}\right)$ as $h \rightarrow \infty$. As $N \rightarrow \infty$, these $\lambda_{N}$ increase to a finite limit $\lambda$, and on the basis of considerable numerical evidence, Efron conjectured ( $p$. 411) that for a $B C D(p)$ one has the exact equality $\lambda=1+(p-q)^{2}$. This conjecture is proved in the next section. 
II. Proof of Efron's Conjecture

Several important facts from Efron (1971) will be required. We first consider the asymptotic autocovariance function

$$
\rho_{k} \equiv \lim _{n \rightarrow \infty} E\left(T_{h} T_{h+k}\right)
$$

and the associated spectral density

$$
f(w) \equiv \sum_{-\infty}^{\infty} \rho_{k} e^{-i w k}=1+\sum_{k=1}^{\infty} \rho_{k} \cos (k w)
$$

Here we note that $\Sigma\left|\rho_{k}\right|<\infty$ so $f(w)$ exists as a continuous, even function (Efron (1971), p. 410). Also, we note that the definition of $f(w)$ differs by a factor of $2 \pi$ from the usual formula for a spectral density.

A key observation of Efron (1971) is that $\lambda$ can be expressed in terms of $f(w)$.

Lemma 1. The maximum of $f(w)$ equals $\lambda$.

The calculation of this maximum then hinges on the following results.

Lemma 2. Setting $r=p / q$, we have $\rho_{0}=1, \rho_{1}=-\frac{(r-1)^{2}}{2 r(r+1)}$, and $\rho_{2}-\rho_{1}=\frac{(r-1)^{3}}{2 r(r+1)^{2}}$.

Lemma 3. For $k \geq 1, \rho_{k}$ is negative and $\rho_{k+1}-\rho_{k}$ is positive and decreasing.

Lemma 4. $f(\pi)=1+\left(\frac{r-1}{r+1}\right)^{2}=1+(p-q)^{2}$. 
The proof of Lemma 1 is given in Efron (1971), pp. 411-412, and Lemmas 2, 3, and 4 are contained in Efron's Theorem 4. (The only cautions are that $\rho_{2}-\rho_{1}$ is perhaps most easily calculated directly from Efron's Lemmas 5 and 6, p. 416, and that $\rho_{1}$ is misprinted as equal to $\rho_{2}-\rho_{1}$ on $p .415$. )

The one missing ingredient is supplied by a general result on trigonometric series (Katznelson (1968), p. 22).

Lemma 5. Suppose $\left\{a_{n}\right\}_{n=-\infty}^{\infty}$ is an even sequence of nonnegative numbers which tend to zero as $n$ tends to infinity. If for all $n>0$

$$
a_{n+1}-2 a_{n}+a_{n-1} \geq 0
$$

then the series

$$
g(x)=\sum_{n=-\infty}^{\infty} a_{n} e^{-i n t}
$$

represents a nonnegative, integrable function.

The facts have now been so arranged that it becomes easy to prove Efron's conjecture. Setting $g(x)=f(\pi)-f(x)$ one sees that showing $\max f(x)=f(\pi)=1+(p-q)^{2}$ is equivalent to proving $g(x) \geq 0$. Writing $g(x)=\sum_{n=-\infty}^{\infty} a_{n} e^{-i n t}$, we have $a_{0}=(p-q)^{2}=\left(\frac{r-1}{r+1}\right)^{2}$ and $a_{n}=-\rho_{n}$ for $n \neq 0$. By Lemma 3 , the $a_{n}$ are positive; and since $\Sigma\left|\rho_{n}\right|<\infty$, the $a_{n}$ tend to zero as $n$ tends to infinity. Also, by Lemma 3 we have $a_{n+1}-2 a_{n}+a_{n-1} \geq 0$ for $n>1$, since this is the same as $\rho_{k+1}-\rho_{k}$ decreasing for $k \geq 1$. To apply Lemma 5, it only remains to check $a_{2}-2 a_{1}+a_{0} \geq 0$. But, by Lemma 2 , 


$$
\begin{aligned}
a_{2}-2 a_{1}+a_{0} & =-\frac{(r-1)^{3}}{2 r(r+1)^{2}}-\frac{(r-1)^{2}}{2 r(r+1)}+\left(\frac{r-1}{r+1}\right)^{2} \\
& =\frac{(r-1)^{2}}{r(r+1)^{2}} \geq 0,
\end{aligned}
$$

so all conditions of Lemma 5 are satisfied. This shows $g(x)$ is nonnegative and therefore completes the proof of the conjecture. 


\section{References}

Efron, B. (1971). Forcing a sequential experiment to be balanced, Biometrika 58 (3), 403-417.

Katznelson, Y. (1968). An Introduction to Harmonic Analysis, John Wiley and Sons, New York.

Matts, J.P. and McHugh, R.B. (1978). Analysis of accrual randomized clinical trials with balanced groups in strata, J. Cronic Diseases 31 (12), 725-740.

Pocock, S.J. (1979). Allocation of patients to treatment in clinical trials, Biometrics 35 (1), 183-197.

Pocock, S.J. and Simon, R. (1975). Sequential treatment assignments with balancing for prognostic factors in controlled clinical trials, Biometrics 31 (1), 103-115.

Wei, L.J. (1978). Adaptive biased coin design for sequential experiments, Annals of Statistics 6 (1), 92-100.

Wei, L.J. (1977). Class of designs for sequential clinical trials, J. Amer. Statistical Association 72 (358), 382-386. 